\title{
Recycled roots of Hadean protocrust - A possible OIB endmember?
}

\author{
JONAS TUSCH ${ }^{1}$, DR. J. ELIS HOFFMANN ${ }^{2}$, ERIC \\ HASENSTAB $^{3}$ AND CARSTEN MÜNKER ${ }^{4}$
}

\author{
${ }^{1}$ University of Cologne \\ ${ }^{2}$ Freie Universität Berlin \\ ${ }^{3}$ Universität zu Köln \\ ${ }^{4}$ Institut für Geologie und Mineralogie \\ Presenting Author: j.tusch@uni-koeln.de
}

In recent models, deficits of ${ }^{182} \mathrm{~W}$ in modern OIBs are explained by a primordial reservoir in the lower mantle that mixes with classical mantle endmember components DMM, EM1, EM2, and HIMU [1]. Yet the exact origin of the low ${ }^{182} \mathrm{~W}$ endmember in modern OIBs is not known. Popular models argue that negative ${ }^{182} \mathrm{~W}$ isotope anomalies originate from core-mantle interaction either by chemical exchange or by isotopic equilibration [2,3]. Understanding the origin of this mantle reservoir and its evolution in the geologic past is of great importance to resolve the ${ }^{182} \mathrm{~W}$ dichotomy between modern OIBs and most Archean mafic rocks that largely display positive ${ }^{182} \mathrm{~W}$ anomalies. Notably, Archean rocks from the Kaapvaal Craton, southern Africa, are unique in this regard, as they were shown to be the only known Archean rocks displaying negative ${ }^{182} \mathrm{~W}$ isotope anomalies. To better understand the origin of these ancient signatures we performed high-precision ${ }^{182} \mathrm{~W}$ isotope measurements on a wide selection of rocks from the Kaapvaal Craton that were previously analyzed for ${ }^{142} \mathrm{Nd}$ [4] and combine our results with constraints from long-lived ${ }^{176} \mathrm{Hf}-{ }^{143} \mathrm{Nd}-{ }^{138} \mathrm{Ce}$ and trace element systematics to better characterize their parental mantle sources. All these parameters were then combined to develop a geodynamic model that reconciles all observational constraints. We can show that lower crustal Hadean-Early Archean restites from prolonged TTG formation were recycled into the upper mantle and significantly contributed to mafic magmatism in the Kaapvaal Craton. If preserved in the modern mantle, such recycled components may even account for ${ }^{182} \mathrm{~W}$ deficits in modern OIBs. In this regard, our model constitutes a viable alternative explaining the origin of primordial components in the source region of modern OIBs, thus bridging between ${ }^{182} \mathrm{~W}$ isotope systematics in Archean mantle derived rocks and their modern-day counterparts.

[1] Jackson et al. (2020) PNAS

[2] Mundl-Petermeier et al. (2020) GCA

[3] Rizo et al. (2019) GPL

[4] Schneider et al. (2018) EPSL 